\title{
The Forcing of Mercury Oxidation as a Means of Promoting Low-Cost Capture
}

\author{
Final Report \\ Start Date: September 24, 2001 \\ End Date: September 23, 2002 \\ Authors: John C. Kramlich and Linda Castiglone \\ Issued March 2004 \\ DOE Grant No. DE-FG26-01NT41288 \\ Department of Mechanical Engineering \\ University of Washington \\ Box 352600 \\ Seattle, Washington 98195-2600
}




\section{Disclaimer}

This report was prepared as an account of work sponsored by an agency of the United States Government. Neither the United States Government nor any agency thereof, nor any of their employees, makes any warranty, express or implied, or assumes any legal liability or responsibility for the accuracy, completeness, or usefulness of any information, apparatus, product, or process disclosed, or represents that its use would not infringe privately owned rights. Reference herein to any specific commercial product, process, or service by trade name, trademark, manufacturer, or otherwise does not necessarily constitute or imply its endorsement, recommendation, or favoring by the United States Government or any agency thereof. The views and opinions of the authors expressed herein do not necessarily state or reflect those of the United States Government or any agency thereof. 


\begin{abstract}
Trace amounts of mercury are found in all coals. During combustion this mercury is vaporized and can be released to the atmosphere. This has been a cause for concern for a number of years, and has resulted in a determination by the EPA to regulate and control these emissions. Present technology does not, however, provide inexpensive ways to capture or remove mercury from flue gases.
\end{abstract}

The mercury that exits the furnace in the oxidized form $\left(\mathrm{HgCl}_{2}\right)$ is known to much more easily captured in existing wet pollution control equipment (e.g., wet FGD for $\mathrm{SO}_{2}$ ), principally due to its high solubility in water. Until recently, however, nobody knew what caused this oxidation, or how to promote it. Recent DOE-funded research in our group, along with work by others, has identified the gas phase mechanism responsible for this oxidation. The scenario is as follows. In the flame the mercury is quantitatively vaporized as elemental mercury. Also, the chlorine in the fuel is released as $\mathrm{HCl}$. The direct reaction $\mathrm{Hg}+\mathrm{HCl}$ is, however, far too slow to be of practical consequence in oxidation. The high temperature region does supports a small concentration of atomic chlorine due to disassociation of $\mathrm{HCl}$. As the gases cool (either in the furnace convective passes, in the quench prior to cold gas cleanup, or within a sample probe), the decay in $\mathrm{Cl}$ atom is constrained by the slowness of the principal recombination reaction, $\mathrm{Cl}+\mathrm{Cl}+\mathrm{M} \rightarrow \mathrm{Cl}_{2}+\mathrm{M}$. This allows chlorine atom to hold a temporary, local superequilibrium concentration. Once the gases drop below about $550^{\circ} \mathrm{C}$, the mercury equilibrium shifts to favor $\mathrm{HgCl}_{2}$ over $\mathrm{Hg}$, and this superequilibrium chlorine atom promotes oxidation via the fast reactions $\mathrm{Hg}+\mathrm{Cl}+\mathrm{M} \rightarrow \mathrm{HgCl}+\mathrm{M}$, $\mathrm{HgCl}+\mathrm{Cl}+\mathrm{M} \rightarrow \mathrm{HgCl}_{2}+\mathrm{M}$, and $\mathrm{HgCl}+\mathrm{Cl}_{2} \rightarrow \mathrm{HgCl}_{2}+\mathrm{Cl}$. Thus, the high temperature region provides the $\mathrm{Cl}$ needed for the reaction, while the quench region allows the $\mathrm{Cl}$ to persist and oxidize the mercury in the absence of decomposition reactions that would destroy the $\mathrm{HgCl}_{2}$.

Promoting mercury oxidation is one means of getting high-efficiency, "free" mercury capture when wet gas cleanup systems are already in place. The chemical kinetic model we developed to describe the oxidation process suggests that oxidation can be promoted by introducing trace amounts of $\mathrm{H}_{2}$ and/or $\mathrm{CO}$ within the quench region. The reaction of these fuels leads to free radicals that promote the selective conversion of $\mathrm{HCl}$ to $\mathrm{Cl}$, which can then subsequently react with $\mathrm{Hg}$.

The work reported here from our Phase I Innovative Concept grant demonstrated this phenomenon, but it also showed that the process must be applied carefully to avoid promoting the recombination of $\mathrm{Cl}$ back to $\mathrm{HCl}$. For example, addition of $\mathrm{H}_{2}$ at too high a temperature is predicted to actually decrease $\mathrm{Cl}$ concentrations via $\mathrm{Cl}+\mathrm{H}_{2} \rightarrow \mathrm{HCl}+\mathrm{H}$. At lower temperatures this reaction is slowed due to its activation energy. Thus, within the correct window, the process becomes selective for $\mathrm{Cl}$ promotion. Key parameters are the injection temperature of the promoter, the amount of the fuel added.

A successful process based on this research will add a powerful tool to the mercury control arsenal. Presently, fractional oxidation in flue gases varies widely, but averages about $50 \%$. The amounts of promoter needed to obtain quantitative oxidation are predicted to be small ( $\sim 50$ $\mathrm{ppm}$ ). The $\mathrm{H}_{2} / \mathrm{CO}$ could be supplied by conventional natural gas reformer on site, and the low expected fuel concentration would require only a relatively trivial amount of natural gas, even 
for a large power plant. For example, a $600 \mathrm{MW}_{\mathrm{e}}$ plant would require the order of only $1 \mathrm{MW}$ thermal equivalent of natural gas. If the mercury in the stream approaching a FGD system is highly oxidized, then high captures could be achieved without any additional cost, even for fuels of low chlorine. 


\section{Table of Contents}

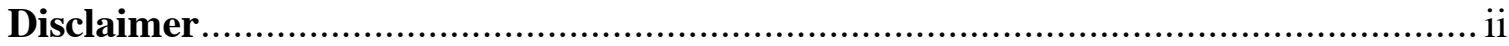

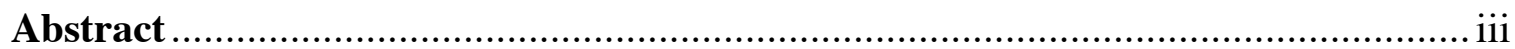

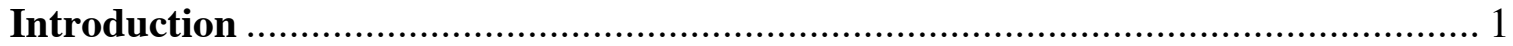

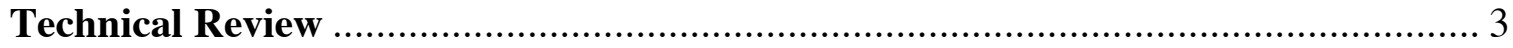

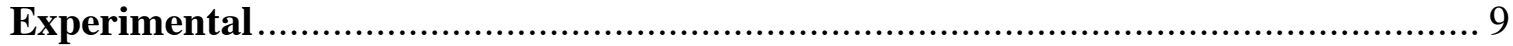

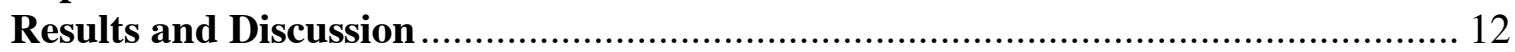

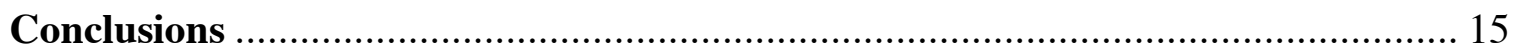

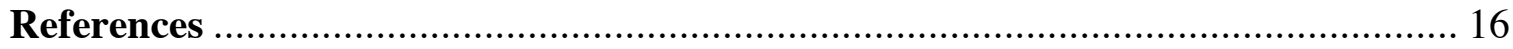

\section{List of Figures}

Figure 1. Equilibrium mercury oxidation behavior ……………................................. 3

Figure 2. Comparison of data with predictions from the kinetic model (literature, Hall et al., 1991) .............................................................. 6

Figure 3. Chemical kinetic model results on the influence of quench rate on

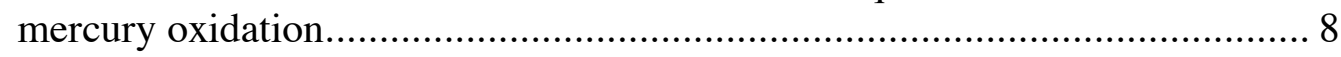

Figure 4. Schematic cross-section of the quartz flow reactor. ...................................... 10

Figure 5. Influence of $50 \mathrm{ppm}_{2}$ on mercury oxidation behavior ............................... 12

Figure 6. Influence of $100 \mathrm{ppm} \mathrm{CO}$ on mercury oxidation behavior.............................. 13

Figure 7. Influence of $100 \mathrm{ppm} \mathrm{CO}$ and $20 \mathrm{ppm} \mathrm{H}_{2}$ on mercury oxidation. Also shown are the previous results for pure $\mathrm{CO}$................................................ 14

\section{List of Tables}

Table 1. Kinetic Data from NIST Database ……………........................................ 5

Table 2. Reactor Gas Composition ....................................................................... 11 


\section{Introduction}

In mid December of 2000, the EPA determined that mercury vapor emissions from electric utility generating stations would come under regulation. While it will be some time before the nature and extent of these regulations are known, they are expected to impose a substantial challenge for existing electric generators and for generation plants for the future. The hope of capturing mercury before it is emitted into the atmosphere rests in understanding its behavior and in taking advantage of this understanding to ensure retention in the least costly way possible. The work presented here explores one such opportunity that has been exposed by our previous DOE funded research.

Mercury vapor emissions are generally accepted to fall into one of two forms: elemental mercury and bivalent mercury (often presumed to be mercuric chloride, $\mathrm{HgCl}_{2}$ ). The elemental form is relatively unreactive and is insoluble in water, factors which limit the effectiveness of most postcombustion control options. The bivalent form is water soluble, which often allows good capture in wet systems.

Mercury control technologies have been an area of substantial interest in the last few years, as illustrated by the following examples. The addition of activated carbon in to a spray drier system leads to greater than 90\% removal in some tests (Gleiser and Felsvant, 1994; Serre et al., 2000), while the use of iodine or sulfur impregnation on the activated carbon leads to much higher captures of elemental mercury (Guijarro et al., 1998; Mendioroz et al., 1999; Hsu et al., 2000). While this technology is effective, the very high cost $(\$ 14,200-22,100$ per pound of mercury removed; Environmental Protection Agency, 1997) has motivated the search for other approaches. Zeolites have been investigated as sorbents (Morency et al., 2000), as have dry alkaline sorbents originally designed for $\mathrm{SO}_{2}$ and $\mathrm{HCl}$ capture (Ghorishi and Gullett, 1998; Gullett et al., 2000). Only a few approaches for directly capturing elemental mercury have been proposed. For example, one proposal makes use of gold doping onto activated carbon to promote capture of mercury as an amalgam (Durham et al., 1994).

One fertile field for obtaining low cost capture is to make use of existing pollution control equipment. For example, wet FDG systems are relatively effective against oxidized mercury, but they only incompletely capture elemental mercury (Meij, 1991). The challenge for these systems is to promote mercury oxidation. Some advanced approaches show promise, but remain the subject of uncertainty with respect to cost. One approach makes use of a pulsed corona discharge to promote mercury oxidation (Masuda, 1993). Widmer et al. (2000) estimated that this approach would require about $1 \%$ of a given power plant's electrical output. Another approach under consideration is the use of catalysts to promote oxidation ahead of wet FGD systems (Richardson et al., 2000).

If one were to wish for an optimal approach, it would make use of existing pollution control equipment coupled with a low cost, low impact means of promoting oxidation of mercury into the easily captured bivalent form. The approach we investigated here makes use of the recently uncovered chemical kinetic details of the oxidation process. Here, a relatively small amount of natural gas is reformed into $\mathrm{CO}$ and $\mathrm{H}_{2}$, and this stream is introduced at a point in the convective section of the furnace. The oxidation of the $\mathrm{CO}$ and $\mathrm{H}_{2}$ produces free radicals that promote the 
oxidation. The oxidation mechanism underlying this approach is surprisingly complex, and only recently has work in our laboratory (Sliger et al., 2000a,b) and elsewhere (Senior et al., 2000; Widmer et al., 2000) defined the details of the chemistry (this will be described in the next section).

The work under our Phase I Innovative Concepts grant has shown that significant oxidation can be promoted. It has also shown that if applied incorrectly the $\mathrm{CO}$ and $\mathrm{H}_{2}$ can actually promote reduction to elemental $\mathrm{Hg}$. The key parameters are the temperature at which the promoter is added and the amount of promoter. 


\section{Technical Review}

This section first summarizes the elementary reactions governing mercury oxidation. These are then combined with other reactions describing chlorine behavior, and this overall mechanism is used to explain homogeneous mercury oxidation. This new understanding of oxidation behavior is then used to suggest the technical basis for enhancing oxidation that was the basis for the Phase I work presented here.

\section{Summary of Homogeneous Mercury Oxidation Behavior}

Experiments have clearly demonstrated that homogeneous oxidation of mercury by chlorine species occurs. Both $\mathrm{HCl}$ and $\mathrm{Cl}_{2}$ have been shown to be active in promoting global oxidation. $\mathrm{HCl}$ is of particular importance since it is the predominant end product of fuel-chlorine under practical combustion conditions. The following discussion first outlines equilibrium mercury behavior, and then the elementary chemical kinetics of mercury oxidation under boiler conditions.

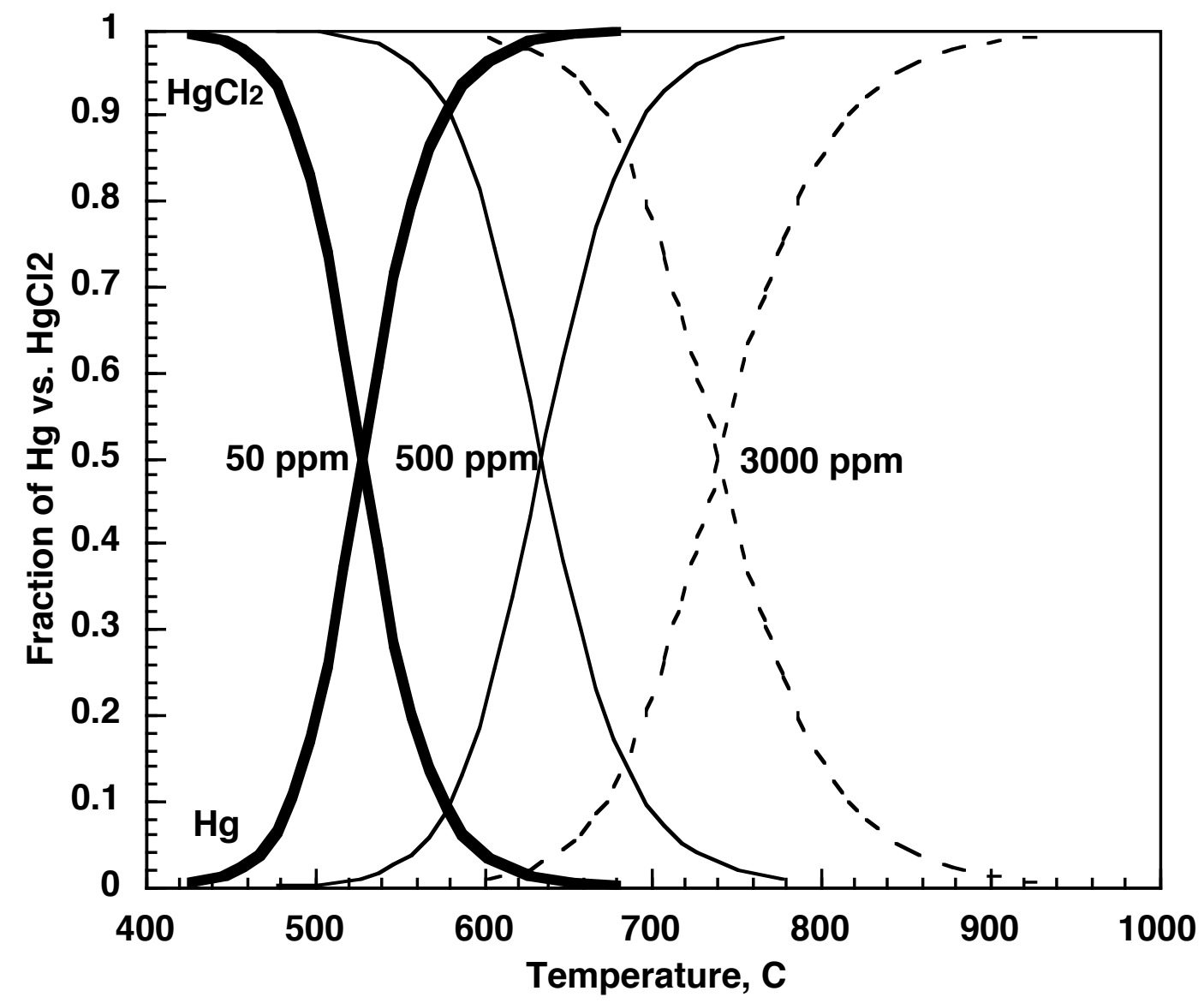

Figure 1. Equilibrium mercury oxidation behavior.

At combustion temperatures, equilibrium calculations show mercury exists as elemental vapor. The kinetic rates are high enough at these temperatures that equilibrium represents a good model for behavior. Thus, all the mercury exiting the flame region initially exists in the elemental 
form. Figure 1 shows equilibrium predictions for the speciation of mercury as these gases cool under three $\mathrm{HCl}$ concentrations. These calculations included other mercury species and are performed against background concentrations of other gases that are typical of coal furnace flue gas (the small $\mathrm{HgO}$ contribution to oxidized mercury is included with the $\mathrm{HgCl}_{2}$ numbers). Figure 1 shows that as the gases cool, the favored equilibrium product shifts to mercuric chloride $\left(\mathrm{HgCl}_{2}\right)$. This crossover temperature for $\mathrm{HgCl}_{2}$ increases from $525^{\circ} \mathrm{C}$ to $640^{\circ} \mathrm{C}$ as the background $\mathrm{HCl}$ goes from 50 to $500 \mathrm{ppm}$. This crossover point is not influenced by mercury concentration as long as hydrochloric acid is present in excess, which is the usual case. These trends are consistent with reports in the literature (Rizeq et al, 1994; Gullett, 1994).

The elementary reaction of $\mathrm{Hg}$ with $\mathrm{HCl}$ must be considered since $\mathrm{HCl}$ is the predominant chlorine species under practical flame and post-flame conditions. The direct reaction:

$$
\mathrm{Hg}+\mathrm{HCl} \rightarrow \mathrm{HgCl}+\mathrm{H}
$$

is not important, however, due to its strong endothermicity and high energy barrier (Hranisavljevic and Fontijn, 1997). Widmer et al. (2000) estimate an upper limit rate constant via a collision-limit preexponential term and an activation energy equivalent to the $\Delta \mathrm{h}$ for the reaction:

$$
\mathrm{k}_{1}=4.94 \mathrm{E}+14 \bullet \exp (-39,910 / \mathrm{T})
$$

This results in an insignificant rate under all relevant conditions. Thus, the elementary oxidation reactions must involve other species that are derived from $\mathrm{HCl}$.

The observation that the global oxidation of mercury by $\mathrm{HCl}$ is promoted by high temperature suggests that the key species may be reactive free radicals or other species that are derived from $\mathrm{HCl}$. The concentration of such a radical would be expected to be strongly dependent on temperature. One likely candidate is atomic chlorine.

The fast oxidation of mercury at room temperature via:

$$
\mathrm{Hg}+\mathrm{Cl} \rightarrow \mathrm{HgCl}
$$

has been reported in the literature with $\mathrm{k}_{2}=1.95 \pm 1.05 \times 10^{13} \mathrm{~cm}^{3} /$ mole-s (Horne et al., 1968). The rate constant is within an order of magnitude of the collision limit, which is not unexpected for such an exothermic free radical reaction. Widmer et al. (2000) derive a rate expression for this reaction by using mechanistic estimates for other reactions in the mercury/chlorine system and then adjusting the Arrhenius parameters for Reaction 2 until they matched their data. This results in a rate constant about 15 times higher than the Horne et al. result. Although the uncertainty associated with this very indirect approach must be considered, the results do suggest a fast reaction. The key problem is then obtaining an accurate estimate for $\mathrm{Cl}$-atom behavior.

A second oxidation reaction is with $\mathrm{Cl}_{2}$. The direct, room temperature oxidation of mercury by $\mathrm{Cl}_{2}$ was observed by Hall et al. (1991), which suggests a fast reaction. Further results showed 
that the presence of the flue gas constituents $\left(e . g ., \mathrm{CO}_{2}, \mathrm{H}_{2} \mathrm{O}, \mathrm{O}_{2}\right)$ interfered with this mercury oxidation process.

Widmer et al. (2000) suggest that the elementary reaction is:

$$
\mathrm{Hg}+\mathrm{Cl}_{2} \rightarrow \mathrm{HgCl}+\mathrm{Cl}
$$

which leads to chlorine atoms that can quickly react via Reaction 2. At high temperatures, however, $\mathrm{Cl}_{2}$ is not a favored species, and it appears only when the gases quench towards room temperature. As we shall shortly see, $\mathrm{Cl}_{2}$ may indeed play a role at these lower temperatures.

The subsequent oxidation of $\mathrm{HgCl}$ to $\mathrm{HgCl}_{2}$ could occur via several paths, including:

$$
\begin{gathered}
\mathrm{HgCl}+\mathrm{HCl} \rightarrow \mathrm{HgCl}_{2}+\mathrm{H} \\
\mathrm{HgCl}+\mathrm{Cl}_{2} \rightarrow \mathrm{HgCl}_{2}+\mathrm{Cl} \\
\mathrm{HgCl}+\mathrm{Cl} \rightarrow \mathrm{HgCl}_{2}
\end{gathered}
$$

Although an abstraction path must be considered for the latter reaction:

$$
\mathrm{HgCl}+\mathrm{Cl} \rightarrow \mathrm{Hg}+\mathrm{Cl}_{2}
$$

Due to the high concentration of $\mathrm{HCl}$ in the system, Reaction 4 was considered in detail via $a b$

\begin{tabular}{|c|c|c|c|c|c|c|c|c|c|}
\hline & & & & & & & $\mathrm{A}$ & $\mathrm{n}$ & $\mathrm{E}$ \\
\hline CL & CL & M & $\rightarrow$ & CL2 & & M & 14.400 & 0.0 & -1.8 \\
\hline $\mathrm{H}$ & $\mathrm{CL}$ & M & $\rightarrow$ & $\mathrm{HCL}$ & & M & 17.000 & 0.0 & 0.0 \\
\hline $\mathrm{HCL}$ & $\mathrm{H}$ & & $\rightarrow$ & H2 & $\mathrm{CL}$ & & 13.360 & 0.0 & 3.5 \\
\hline $\mathrm{H}$ & CL2 & & $\rightarrow$ & HCL & $C L$ & & 13.930 & 0.0 & 1.2 \\
\hline 0 & $\mathrm{HCL}$ & & $\rightarrow$ & $\mathrm{OH}$ & $\mathrm{CL}$ & & 3.53 & 2.87 & 3.51 \\
\hline $\mathrm{OH}$ & $\mathrm{HCL}$ & & $\rightarrow$ & $C L$ & $\mathrm{H} 2 \mathrm{O}$ & & 7.43 & 1.65 & -.223 \\
\hline 0 & CL2 & & $\rightarrow$ & CLO & $\mathrm{CL}$ & & 12.790 & 0.0 & 3.585 \\
\hline 0 & CLO & & $\rightarrow$ & $\mathrm{CL}$ & $\mathrm{O} 2$ & & 13.2 & 0.0 & -.193 \\
\hline CL & $\mathrm{HO} 2$ & & $\rightarrow$ & HCL & $\mathrm{O} 2$ & & 13.030 & 0.0 & .894 \\
\hline CL & $\mathrm{HO} 2$ & & $\rightarrow$ & $\mathrm{OH}$ & CLO & & 13.39 & 0.0 & -.338 \\
\hline CL & $\mathrm{H} 2 \mathrm{O} 2$ & & $\rightarrow$ & $\mathrm{HCL}$ & HO2 & & 12.800 & 0.0 & 1.951 \\
\hline CLO & $\mathrm{H} 2$ & & $\rightarrow$ & HOCL & $\mathrm{H}$ & & 11.78 & 0.0 & 14.1 \\
\hline $\mathrm{H}$ & HOCL & & $\rightarrow$ & $\mathrm{HCL}$ & $\mathrm{OH}$ & & 13.980 & 0.0 & 7.62 \\
\hline CL & HOCL & & $\rightarrow$ & $\mathrm{HCL}$ & CLO & & 12.260 & 0.0 & .258 \\
\hline CL2 & $\mathrm{OH}$ & & $\rightarrow$ & $C L$ & HOCL & & 12.100 & 0.0 & 1.81 \\
\hline 0 & HOCL & & $\rightarrow$ & $\mathrm{OH}$ & CLO & & 12.780 & 0.0 & 4.372 \\
\hline $\mathrm{OH}$ & HOCL & & $\rightarrow$ & $\mathrm{H} 2 \mathrm{O}$ & CLO & & 12.255 & 0.0 & .994 \\
\hline HOCL & & M & $\rightarrow$ & $\mathrm{OH}$ & $C L$ & M & 10.250 & -3.0 & 56.72 \\
\hline
\end{tabular}
inito techniques in one of our publications (Sliger et al., 2000a) and was found to be insignificant due to the high energy barrier needed to break $\mathrm{HCl}$.

Table 1

Kinetic Data from NIST Database

$\mathrm{cm}$, mole, s units. Units on $\mathrm{E}$ are $\mathrm{kcal} /$ mole 
These mercury reactions were combined with the $\mathrm{H}_{2} / \mathrm{O}_{2} / \mathrm{CO} / \mathrm{CO}_{2}$ reaction set from Warnatz et al. (1996) along with the reactions involving $\mathrm{Cl}, \mathrm{Cl}_{2}, \mathrm{HCl}, \mathrm{ClO}, \mathrm{HOCl}$, from the NIST data base NIST, 1999) to produce the complete chemical kinetic mechanism.

A series of calculations were performed to simulate various literature flow reactor mercury oxidation data sets (Hall et al., 1991; Widmer et al., 1998), as well as our own data (Sliger et al., 2000a,b; Sliger, 2001). These were all modeled as plug flow reactors with equilibrium compositions at the high-temperature inlet and with all the chlorine as $\mathrm{HCl}$. The plug flow reactors utilized the reported (or measured for our data) temperature profiles, with these profiles followed right down to the room temperature inlet to the measurement systems.

Figure 2 shows an example of the comparison of our experimental results (Sliger et al., 2000a) and those of Hall et al. (1991) with the model. Similar good agreement is obtained with the other data sets. We can now answer the question of how mercury is homogeneously oxidized.

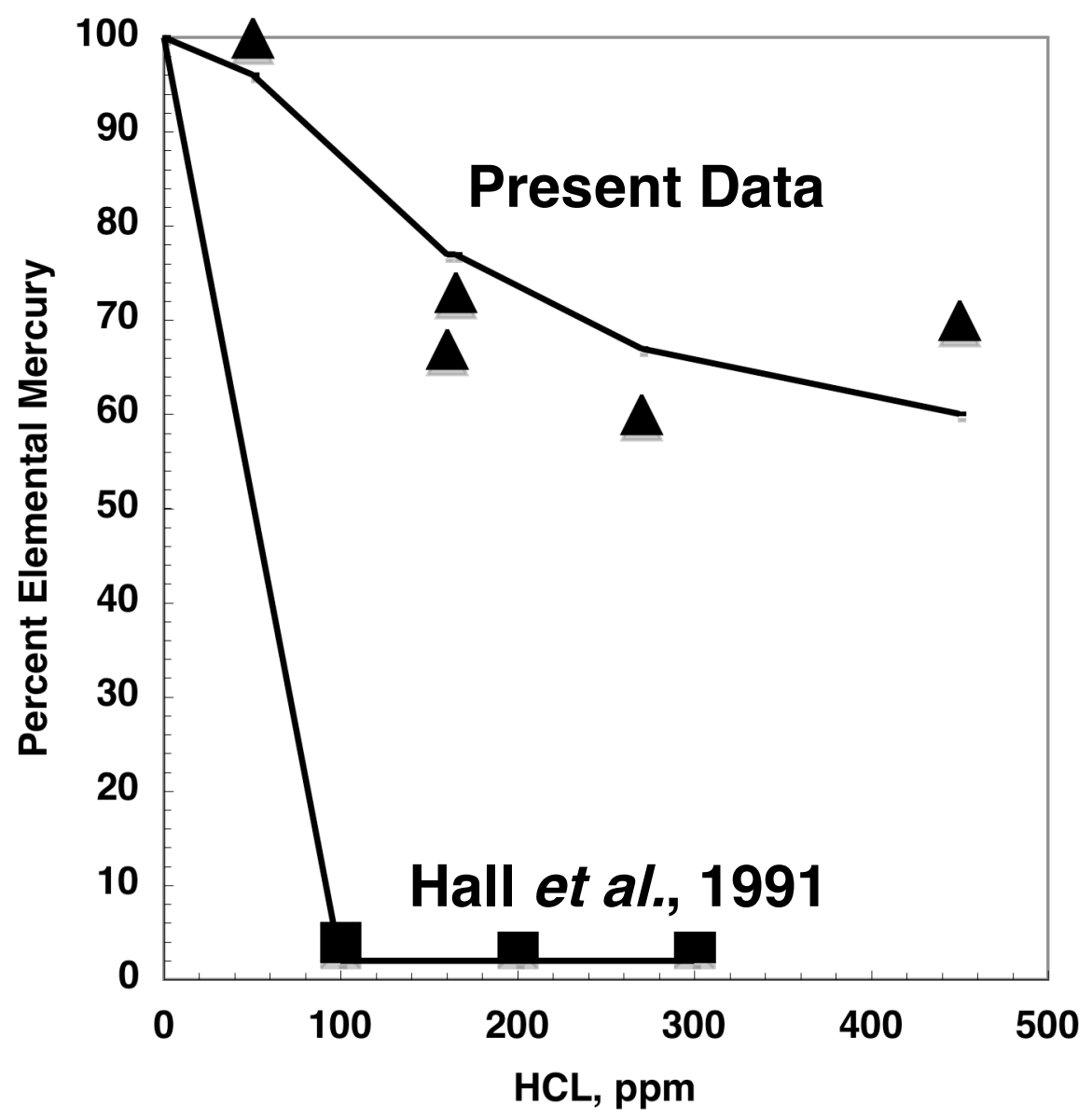

Figure 2. Comparison of data with predictions from the kinetic model (literature, Hall et al., 1991). 
The chemical kinetic model supports the following oxidation scenario:

- At high temperature $\left(>800^{\circ} \mathrm{C}\right)$, mercury exists in the elemental form. Although $\mathrm{Cl}$ is available at these temperatures, and the reaction $\mathrm{Hg}+\mathrm{Cl}$ proceeds, the high instability of $\mathrm{HgCl}$ and $\mathrm{HgCl}_{2}$ under these conditions leads to no net oxidized mercury oxidation. Note that this implies that at the outlet of the high-temperature portion of Hall's reactor, no oxidized mercury exists, even though the measurement suggests almost complete oxidation. This point is consistent with equilibrium.

- At the same point, $\mathrm{Cl}$-atom concentrations are near their equilibrium value.

- During thermal quench, a kinetic limit on the recombination reaction $\left(\mathrm{Cl}+\mathrm{Cl}+\mathrm{M} \rightarrow \mathrm{Cl}_{2}+\mathrm{M}\right)$ leads to the actual $\mathrm{Cl}$-atom concentration decaying at a much slower rate than the equilibrium concentration. This results in a local superequilibrium in $\mathrm{Cl}$-atom.

- When the temperature has been reduced to the point where $\mathrm{HgCl}_{2}$ is no longer unstable $\left(\sim 500^{\circ} \mathrm{C}\right)$, mercury is oxidized via $\mathrm{Hg}+\mathrm{Cl}, \mathrm{HgCl}+\mathrm{Cl}$, and $\mathrm{HgCl}+\mathrm{Cl}_{2}$.

- The possibility remains for $\mathrm{Hg}+\mathrm{Cl}_{2}$ (produced by $\mathrm{Cl}$-atom recombination) to produce $\mathrm{HgCl}$, although this is not presently indicated for our conditions.

This scenario suggests that all the oxidized mercury is generated within the cool-down region between the hot reactor exit and the inlet to the room-temperature measurement apparatus. Since all mercury analysis is presently done at room temperature, the combustion gases must pass through a quench before being characterized, and our hypothesis is that this is where mercury oxidation occurs. Figure 3 shows that the same behavior is obtained whether this thermal quench is at a rate characteristic of a sample probe, or at a rate similar to that occurring within a boiler.

The scenario has successfully explained many of the trends seen in the data, e.g.:

- Why is oxidation apparently favored by higher temperatures (contradicting equilibrium)? The higher temperatures are needed to generate the $\mathrm{Cl}$-atom needed for direct oxidation and for forming $\mathrm{Cl}_{2}$ for subsequent oxidation.

- Why do the Hall et al. (1991) data indicate so much more oxidation than other data sets at similar residence times and temperature (see Figure 2)? The Hall data were taken without water vapor in the experiment, and the model shows that equilibrium $\mathrm{Cl}$-atom is over an order of magnitude higher in dry systems.

- Why does oxidation increase with $\mathrm{HCl}$ concentration, even though the $\mathrm{HCl}$ present is always in vast excess relative to the $\mathrm{Hg}$ ? Although $\mathrm{HCl}$ is present in excess, the $\mathrm{Cl}$-atom and $\mathrm{Cl}_{2}$ that actually carry out the reaction are not in excess relative to the $\mathrm{Hg}$, and can become depleted, resulting less oxidation as the parent $\mathrm{HCl}$ concentration is reduced.

The next question is to identify the barriers to oxidation and to find ways around these barriers.

\section{Overcoming Barriers to Oxidation}

The preceding discussion identifies the availability of $\mathrm{Cl}$-atom in the quench region as the principal barrier to mercury oxidation. Thus, the goal is to increase $\mathrm{Cl}$-atom concentrations at or above the temperature where oxidation starts to occur. 


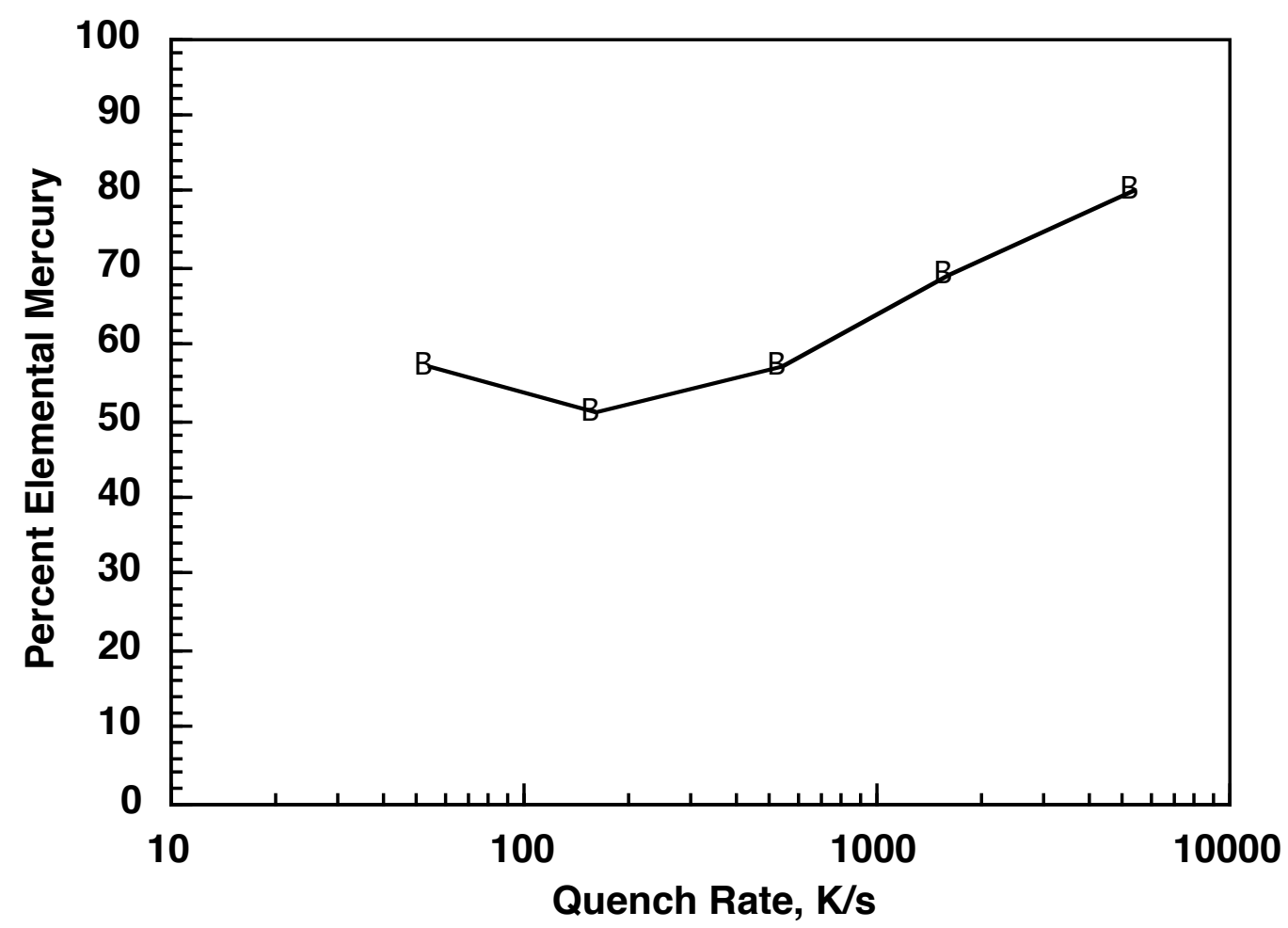

Figure 3. Chemical kinetic model results on the influence of quench rate on mercury oxidation.

In fuel-lean gases, the introduction of $\mathrm{H}_{2}$ into the quench region is indicated as increasing $\mathrm{OH}$ concentrations via the chain branching sequence:

$$
\begin{gathered}
\mathrm{H}_{2}+\mathrm{OH}-->\mathrm{H}_{2} \mathrm{O}+\mathrm{H} \\
\mathrm{H}+\mathrm{O}_{2}-->\mathrm{OH}+\mathrm{O} \\
\mathrm{O}+\mathrm{H}_{2}-->\mathrm{OH}+\mathrm{H}
\end{gathered}
$$

The $\mathrm{OH}$ in turn promotes $\mathrm{HCl}+\mathrm{OH} \rightarrow \mathrm{Cl}+\mathrm{H}_{2} \mathrm{O}$. The chlorine atom is then available to force oxidation. The kinetics indicate that this process is sensitive to (1) the temperature within the quench region at which the $\mathrm{H}_{2}$ is added and (2) the amount of $\mathrm{H}_{2}$ used. In particular, injection of the $\mathrm{H}_{2}$ at a higher temperature may tend to reduce $\mathrm{Cl}$ by forcing it towards equilibrium (this occurs via $\left.\mathrm{H}_{2}+\mathrm{Cl}-->\mathrm{HCl}+\mathrm{H}\right)$. However, injection of $\mathrm{H}_{2}$ at a lower temperature, and the use of relatively low amounts of $\mathrm{H}_{2}$, leads to a selective promotion of $\mathrm{Cl}$ concentrations (the reaction noted above, $\mathrm{H}_{2}+\mathrm{Cl}$, slows due to its activation energy). The kinetics suggest that $\sim 50 \mathrm{ppm}$ of $\mathrm{H}_{2}$ is appropriate. The goal of the work reported here is to experimentally test this hypothesis. 


\section{Experimental}

The quartz flow reactor is designed to provide a reaction environment of known time/temperature history (including a well-characterized quench of the gases to room temperature) with more flexibility in choosing the reacting gas composition than is available in flame experiments. Our laboratory has been active in mercury measurements since 1995, and we have obtained an awareness of the difficulties of obtaining reliable mercury measurements that comes with long experience (and the inevitable mistakes!). In particular, we are aware of the importance of choosing appropriate materials for all surfaces that contact mercury, and we are aware of the interferences that can occur during mercury measurements.

The gases for the quartz flow reactor originate in commercial storage cylinders and are controlled and metered into the reactor independently. The $\mathrm{HCl}$ cylinder contains $1000 \mathrm{ppm} \mathrm{HCl}$ in nitrogen $\left(\mathrm{N}_{2}\right)$. Water is introduced using a syringe drive. To force evaporation and prevent recondensation, the inlet line is heat-taped from the point of water injection to the quartz reactor. Mercury is introduced by saturating a nitrogen stream that is in contact with liquid mercury. A precision mass flow controller is used to meter nitrogen into the bubbler, and the bubbler is placed in an $86^{\circ} \mathrm{F}\left(30^{\circ} \mathrm{C}\right)$ controlled-temperature water bath to produce a saturated mercury stream. This is immediately diluted by a second $\mathrm{N}_{2}$ stream. These lines are all heat-taped to keep the mercury well above its saturation temperature. All mercury vapor lines consist of borosilicate glass, except for the reactor itself. The reactor is made of fused quartz, and its interior surface is treated with phosphoric acid to avoid the diffusion of $\mathrm{Hg}$ into the quartz. All non- $\mathrm{Hg}$ lines that contain reactive materials are made from Teflon.

Figure 4 shows the quartz reactor. The overall design is based on the flow reactor system developed at the Technical University of Denmark (Kristensen, 1996). This reactor is placed within a cylindrical clamshell oven. Four lines carrying the reactor gases enter the reactor separately. Line 1 provides most of the gas, and it initially flows near the wall of the oven, which generates preheat before the gases mix in the reaction zone. The total length of the reactor is 23.5 inches $(59.7 \mathrm{~cm})$. In the first section of the reactor, lines two, three and four enter the reactor through $2 \mathrm{~mm}$ ID tubes. The flows then go through a $0.5 \mathrm{~mm}$ nozzle. At this point the flows mix with the preheated $\mathrm{HCl}$ and nitrogen from line one, which initiates the contact between mercury and $\mathrm{HCl}$, thus starting the reaction zone. Jet mixing calculations suggest that mixing occurs within the first inch $(2.5 \mathrm{~cm})$. The length from the nozzle to the end of the heated section is 8 inches $(20.3 \mathrm{~cm})$, so the gases have sufficient time to mix within the high temperature zone. The last six inches $(15.2 \mathrm{~cm})$ of the quartz reactor are outside the clamshell oven. Here the gases are quenched to room temperature before analysis.

The quench is accomplished by introducing cooling air into the tube surrounding the sample gas tube, forming a counter-flow heat exchanger. The temperature profile of the sample gas from the nozzle to the end of the quartz reactor has been measured by a type-K thermocouple traverse. The measured quench rate is on the order of $3000 \mathrm{~K} / \mathrm{s}$.

Our standard analysis is via a continuous cold vapor atomic absorption system. Once the sample gas leaves the quartz reactor, it goes through an empty impinger in an ice bath that is used to collect the water that condenses as the sample gas cools. Some researchers have suggested that 


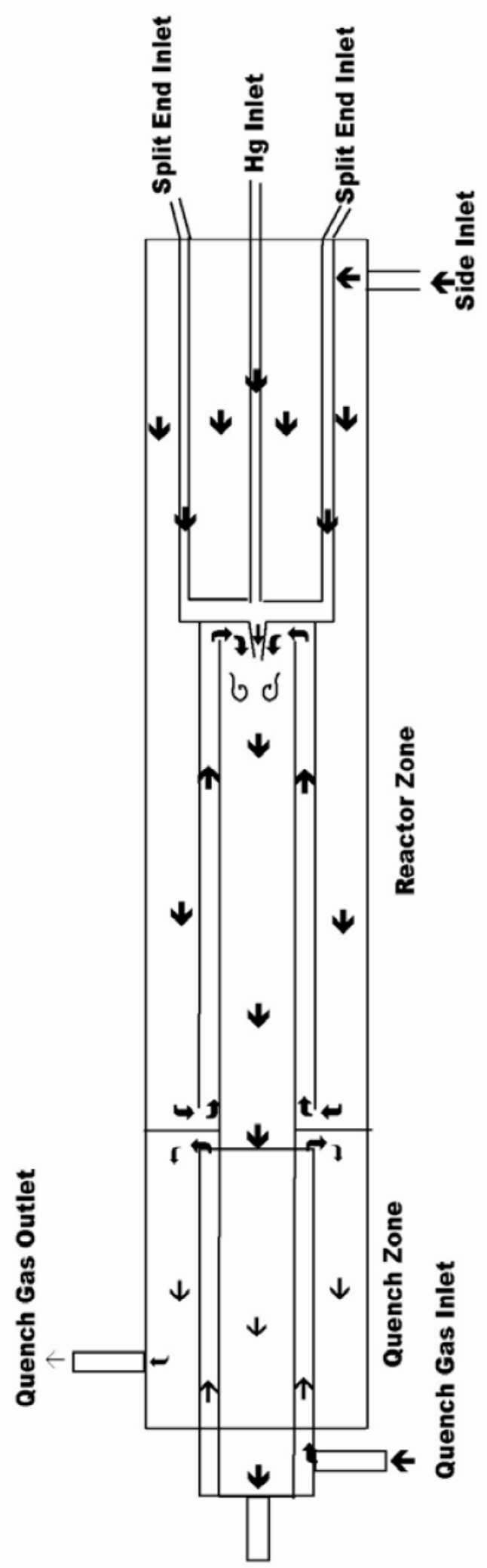

Figure 4. Schematic cross-section of the quartz flow reactor. 
water vapor is an interference with the ultraviolet absorption technique. Literature suggests, however, that water vapor absorption is not a problem. To quote one author: "a detailed examination revealed that water does not absorb at the resonance line of mercury. The observed interferences were due to droplets of solution carried along by the gas stream or by condensation of water vapor in the absorption cell." (Welz, 1985). Thus, it is liquid phase water via a scattering mechanism, rather than water vapor absorption that causes this false mercury reading in the ultraviolet analyzer.

After leaving the impinger, the gas goes into the ultraviolet analyzer (Buck Scientific Model 400A). The normal mode of operation is to toggle the $\mathrm{HCl}$ flow on and off during experiments. Since the analyzer responds only of elemental mercury, this approach provides a continuous measurement of baseline $\mathrm{Hg}$ ( $\mathrm{HCl}$ off), remaining $\mathrm{Hg}$ when $\mathrm{HCl}$ is present, and oxidized $\mathrm{Hg}$ (via difference). We earlier used the Ontario Hydro method (Sliger, 2001), but have largely abandoned it due to the large effort and time needed to generate data. We have, however, demonstrated consistency between the two measurement approaches for a number of experiments. (Sliger, 2001).

Table 2 shows the baseline gas composition used in the experiment.

Table 2. Reactor Gas Composition

\begin{tabular}{c} 
Component \\
\cline { 1 - 1 } $\mathrm{H}_{2} \mathrm{O}$ \\
$\mathrm{O}_{2}$ \\
$\mathrm{HCl}$ \\
$\mathrm{Hg}$ \\
$\mathrm{N}_{2}$ \\
$\mathrm{H}_{2}$ \\
$\mathrm{CO}$
\end{tabular}

\begin{tabular}{c} 
Concentration \\
\hline $5 \%$ \\
$10 \%$ \\
as indicated \\
$900 \mu \mathrm{g} / \mathrm{m}^{3}$ \\
balance \\
as indicated \\
as indicated
\end{tabular}




\section{Results and Discussion}

The promotion approach was tested during Phase I of the Innovative Concept grant that is the subject of this report. The reactor was operated at various temperatures with $50 \mathrm{ppm}$ of $\mathrm{H}_{2}$ added with the reacting gas. Figure 5 shows the results compared to the case where no $\mathrm{H}_{2}$ was added.

The results show no promotion at low temperatures, a significant increase in oxidation around $600^{\circ} \mathrm{C}$, and a significant inhibition of oxidation at the highest temperatures.

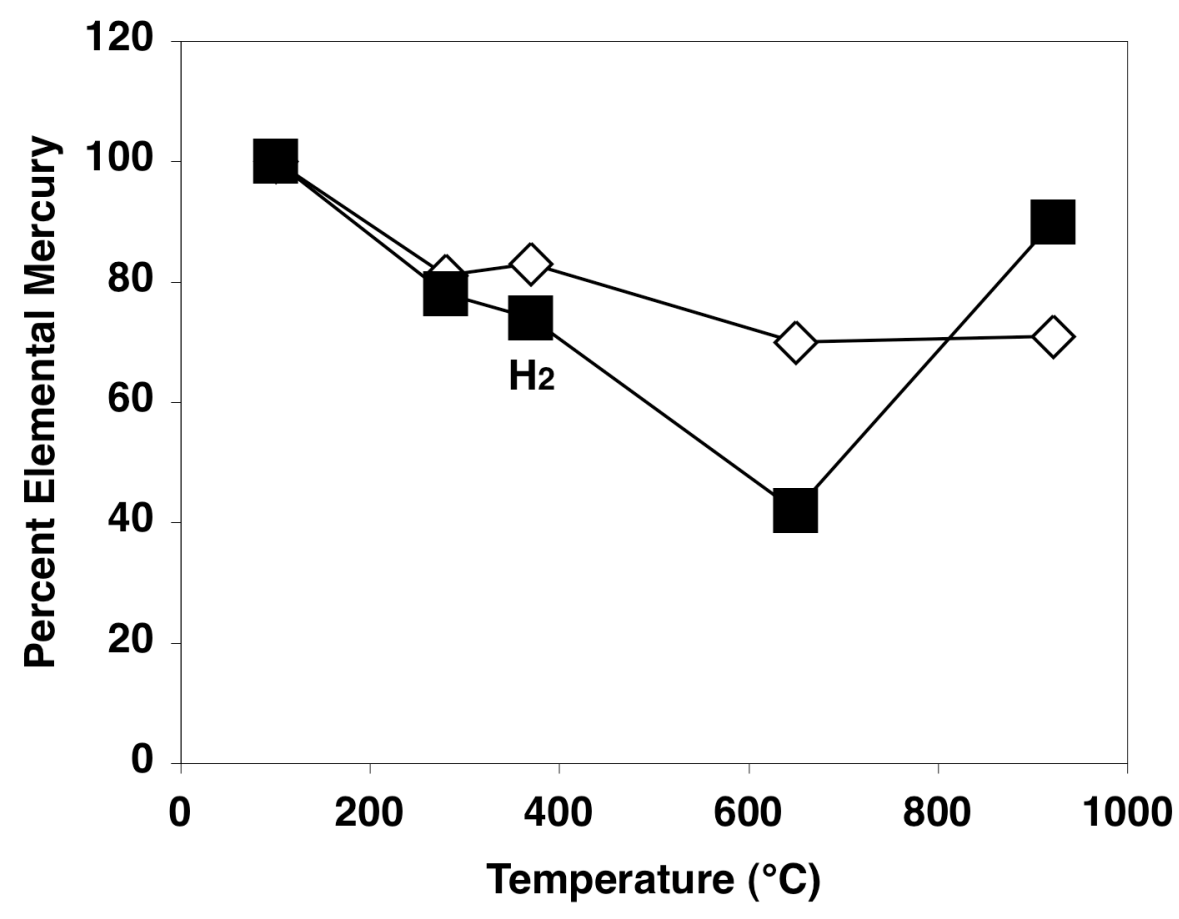

Figure 5. Influence of $50 \mathrm{ppm} \mathrm{H}_{2}$ on mercury oxidation behavior.

At high temperature, the reaction:

$$
\mathrm{H}_{2}+\mathrm{Cl} \rightarrow \mathrm{HCl}+\mathrm{H}
$$

tends to drive the $\mathrm{Cl}$ atom concentrations to their equilibrium level, with the result that oxidation is in fact reduced at the higher injection temperatures. At medium temperatures the oxidation is promoted as described above. At low temperatures, no effect of the $\mathrm{H}_{2}$ is seen as the environment is too cold for $\mathrm{H}_{2}$ reaction. Only at around $600^{\circ} \mathrm{C}$ is oxidation promoted.

In a second series of tests, $100 \mathrm{ppm}$ of $\mathrm{CO}$ was added in place of the $\mathrm{H}_{2}$. The results, plotted in Figure 6, show very little effect. The chemical kinetic model suggests that $\mathrm{CO}$ should promote due to chain branching during $\mathrm{CO}$ oxidation:

$$
\mathrm{CO}+\mathrm{OH} \rightarrow \mathrm{CO}_{2}+\mathrm{H}
$$




$$
\mathrm{H}+\mathrm{O}_{2} \rightarrow \mathrm{OH}+\mathrm{O}
$$

with the $\mathrm{OH}+\mathrm{HCl} \rightarrow \mathrm{Cl}+\mathrm{H}_{2} \mathrm{O}$ providing the additional $\mathrm{Cl}$ needed for mercury oxidation. There is, however, one difference compared to the $\mathrm{H}_{2}$ case. $\mathrm{CO}$ requires a higher temperature to initiate reaction, and chemical kinetic analysis suggests that the $\mathrm{CO}$ is not significantly reacting at the temperature where the $\mathrm{H}_{2}$ promotion is noted $\left(\sim 600^{\circ} \mathrm{C}\right)$. At the higher temperatures where the $\mathrm{CO}$ does react, the kinetic rates are sufficiently fast to cause the chemistry to bring the $\mathrm{Cl}$ into equilibrium rather than promote it, thus leading to either not promotion, or a small inhibition of oxidation.

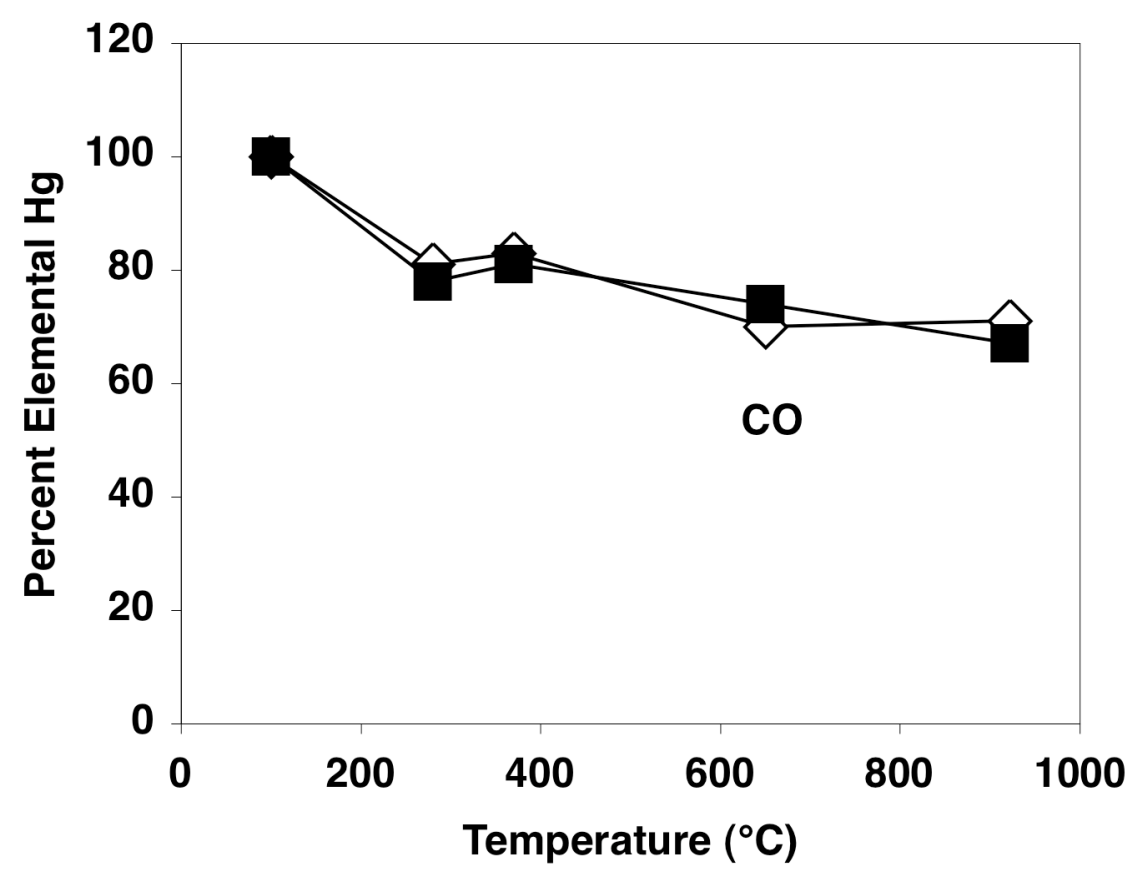

Figure 6. Influence of $100 \mathrm{ppm} \mathrm{CO}$ on mercury oxidation behavior.

One approach to this problem is to mix $\mathrm{H}_{2}$ and $\mathrm{CO}$ together. The idea is to use the $\mathrm{H}_{2}$ chain branching to "pilot" the $\mathrm{CO}$ oxidation at lower temperatures, but to do so with a low enough $\mathrm{H}_{2}$ level to avoid the $\mathrm{Cl}$ scavenging problem. By carefully selecting the $\mathrm{CO} / \mathrm{H}_{2}$ ratio, one can promote $\mathrm{Cl}$ formation from $\mathrm{CO}$ chain branching at lower temperatures than would be possible with $\mathrm{CO}$ alone. Figure 7 shows the results of adding $100 \mathrm{ppm} \mathrm{CO}$ with $20 \mathrm{ppm} \mathrm{of} \mathrm{H}_{2}$. The results indicate that the behavior is very similar to that of $\mathrm{H}_{2}$ alone. In other words, the $\mathrm{CO}$ does not appear to significantly participate in the reaction. 


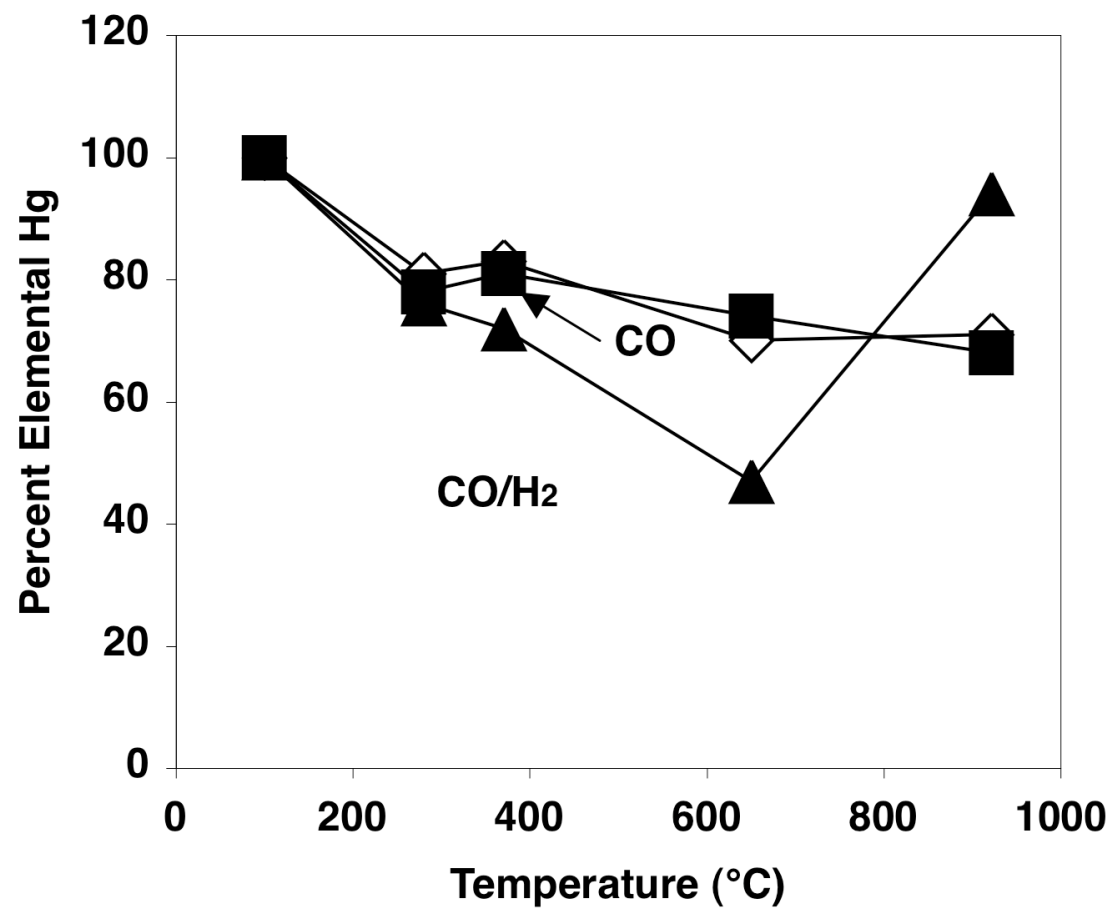

Figure 7. Influence of $100 \mathrm{ppm} \mathrm{CO}$ and $20 \mathrm{ppm} \mathrm{H}_{2}$ on mercury oxidation. Also shown are the previous results for pure $\mathrm{CO}$. 


\section{Conclusions and Recommendations}

The results suggest that $\mathrm{H}_{2}$ can be used to promote mercury oxidation if it is exposed to the mercury $/ \mathrm{HCl}$ vapors under appropriate temperature and concentration. The results also suggest that $\mathrm{CO}$ is not a significant promotion agent. The chemical kinetics suggest that the cause of the promotion is the excess $\mathrm{OH}$ produced by the $\mathrm{H}_{2}$ breakdown. This promotes $\mathrm{OH}+\mathrm{HCl}->\mathrm{Cl}+\mathrm{H}_{2} \mathrm{O}$, with the reactive $\mathrm{Cl}$ available to oxidized $\mathrm{Hg}$.

Several issues must be addressed before this approach can be proposed for practice. First, more testing must be used to establish how much $\mathrm{H}_{2}$ is needed, and to better define the temperature window. Also, testing on $\mathrm{CO}$ must be continued to determine if there are concentration/ temperature regimes where it does influence the process. Then, chemical kinetic modeling must be applied to the entire database to ensure that our present understanding of the chemistry is accurate and adequate. If so, then the models can be used to predict the response that would occur when $\mathrm{H}_{2}$ is injected into the non-isothermal environment of a boiler. For example, our preliminary results suggest that $\mathrm{H}_{2}$ performs best if it is exposed to $\mathrm{Hg} / \mathrm{HCl}$ at $600^{\circ} \mathrm{C}$ in an isothermal environment. This does not mean that a $600^{\circ} \mathrm{C}$ boiler injection temperature is best, as the behavior for injection in a quench region would probably be different. The chemical kinetic calculations can suggest the answer to this question. Finally, the results must be validated in a non-isothermal experiment. From this point practical design implications can be addressed. 


\section{References}

Durham, M. D., Roberts, D. L., Schlager, R. J., CArter, T. G., AND French, P. D., $13^{\text {th }}$ International Conference on Incineration and Thermal Treatment Technologies, Houston, TX (May 1994).

Environmental Protection Agency, "Mercury Study Report to Congress: Overview", http://www.epa.gov/oar/mercover.html (December 1997).

Ghorishi, B., AND Gullet, B. K., "Sorption of Mercury Species by Activated Carbon and Calcium Based Sorbents: Effect of Temperature, Mercury Concentration and Acid Gases”, Waste Management \& Research 6, 582-593 (1998).

Gleiser, R., AND Felsvang, K, "Mercury Emission Reduction using Activated Carbon with Spray Dryer Flue Gas Desulfurization", Proceedings of the American Power Conference. 56, $452-457$ (1994).

Guijarro, M. I., Mendioroz, S., And Munoz, V., "Effect of Morphology of Sulfurized Materials in the Retention of Mercury from Gas Streams", Ind. Eng. Chem. Res. 37, 1088-1094 (1998).

GulletT, B.K., "Sorbent Injection for Dioxin/Furan Prevention and Mercury Control.", Multipollutant Sorbent Reactivity Workshop, Research Triangle Park, North Carolina (July 1994).

Gullett, B. K., Ghorishi, B., Keeney, R., And Huggins, F. E., "Mercuric Chloride Capture by Alkaline Sorbents, $93^{\text {rd }}$ Annual Conference of the Air and Waste Management Association, Paper No. 259, Salt Lake City, UT (June 2000).

Hall, B. Schager, P., Lindqvist, O.: Water, Air and Soil Pollution. 56, 3-14 (1991).

Horne, D.G., Gosavi, R., AND STRAusz, O.P.: The Journal of Chemical Physics, 48, 4758-4764 (1968).

HranisavlJeVic, J., AND Fontisn A., "Kinetics of Ground-State Cd Reactions with $\mathrm{Cl}_{2}, \mathrm{O}_{2}$, and HCl over Wide Temperature Ranges," J. Phys. Chem. 101, 2323-2326 (1997).

Hsu, H.-C., Rostam-Abadi, M., Rood, M. J., Chen, S., And Chang, R., "Preparation of Sulfur-Impregnated Activated Carbon Fibers (ACFs) for Removal of Mercury Vapor from Simulated Coal-Combustion Flue Gases", 93 ${ }^{\text {rd }}$ Annual Conference of the Air and Waste Management Association, Paper No. 435, Salt Lake City, UT (June 2000).

Kristensen, P. G., Glarborg, P, AND DAM-Johansen, K. "Nitrogen chemistry during burnout in fuel-staged combustion", Combustion and Flame 107, 211-222, 1996.

Masuda, S. In: Managing Hazardous Air Pollutants: State of the Art, Chow, W. and Connor, K. K. eds., EPRI TR-101890, Lewis Publishers, Boca Raton, LA (1993).

MEIJ, R., "The Fate of Mercury in Coal-fired Power Plants and the Influence of Wet Flue-gas Desulphurization", Water, Air and Soil Pollution. 56, 21-33 (1991).

Mendioroz, S., Guijarro, M. I., Bermejo, P. J., And Munoz, V., "Mercury Retrieval from Flue Gas by Monolithic Absorbents Based on Sulfurized Sepriolite”, Environ. Sci. Technol. 33, 1697-1702 (1999).

Morency, J. R., PAnagiotou, T., And Senior, C. L., "Laboratory Duct Injection of a ZeoliteBased Mercury Sorbent", 93 ${ }^{\text {rd }}$ Annual Conference of the Air and Waste Management Association, Paper No. 610, Salt Lake City, UT (June 2000).

NIST CHEMICAL KINETIC DATABASE: http://www.cstl.nist.gov/div836/ckmech.html/ (1999). 
Richardson, C., Blythe, G., AND Rhudy, R., "Enhanced Control of Mercury by Wet FGD Systems", $93^{\text {rd }}$ Annual Conference of the Air and Waste Management Association, Paper No. 43, Salt Lake City, UT (June 2000).

RizeQ, R., Hansell, D., AND SeeKer,W., "Predictions of metals emissions and partitioning in coal-fired combustion systems", Fuel Processing Technology. 39, 219-236 (1994).

Senior, C. L., Sarofim, A. F., Zeng, T., Helble, J. J., and Mamani-Paco, R.: Fuel Processing Technology 63, 197-213 (2000).

Serre, S. S., Gullett, B. K., AND Ghorishi, S. B., "Elemental Mercury Capture by Activated Carbon in a Flow Reactor", $93^{\text {rd }}$ Annual Conference of the Air and Waste Management Association, Paper No. 261, Salt Lake City, UT (June 2000).

Sliger, R. N., KRAmlich, J. C., AND MaRINOV. N. M.: Fuel Processing Technology 65, 423438 (2000a).

Sliger, R. N., Kramlich, J. C., Marinov, N. M.: "Development of an elementary homogeneous mercury oxidation mechanism." 93rd Annual Meeting of the Air \& Waste Management Association, Salt Lake City, UT (June 2000b).

SLIGER, R. N.: Development of a Chemical Kinetic Model for the Homogeneous Oxidaiton of Mercury by Chlorine Species: A Tool for Mercury Emissions Control. Ph.D. Dissertation, Department of Mechanical Engineering, University of Washington, Seattle (2001).

Warnatz, J., MaAs, U., AND DibBle, R.W., Combustion, Springer Publishing Company, 67-71 (1996).

Widmer, N. C., Cole, J. A., Seeker, W. R., And Gaspar, J. A., Combustion Science and Technology, 134, 315-326 (1998).

Widmer, N. C., WeSt, J., AND Cole, J. A., "Thermochemical Study of Mercury Oxidation in Utility Boiler Flue Gases", $93^{\text {rd }}$ Annual Conference of the Air and Waste Management Association, Salt Lake City, UT (June 2000).

Welz, BERNHARD, Atomic Absorption Spectrometry, $2^{\text {nd }}$ edition, English translation by Christopher Skegg, Weinheim, Deerfield Beach, Florida, 1985. 